\title{
PRINCIPLES OF FEED BUDGETING
}

\author{
G. A. G. FRENGLEY \\ Lincoln College, Canterbury
}

Abstract

The paper discusses the components of feed budgeting. The main possibilities which can be considered as useful alternatives to equate. feed supplies with stock requirements are described. Comments are also made about the interaction of stock with pasture production, the quantitative approach to feed budgeting, and the use of a clear objective to avoid confusion when discussing the application of the technique.

PERHAPs we are attempting to lend an air of mystique or create a respectably specialized field of interest when we use the term feed budgeting. Feed budgeting is not new, only the term is. As long as animals have been domesticated, shepherds have had to plan how to feed them - either by shifting them to fresh grass or by conserving feed for periods when plant growth was restricted. Even in this most simple form almost all the elements of the feed budgeting problem are present.

\section{THE COMPONENTS OF FEED BUDGETING}

"Feed budgeting" involves an objective function, one or more resources, one or more products and an ex ante problem.

The objective concerns the particular animal product one is attempting to produce at maximum or perhaps optimum levels. It may be meat, wool, or milk, but in any event the end product of an attempt to use feed budgeting techniques is to improve the output of these products and so to maximize profits.

The other components were described as one or more resources and an ex ante problem. The resources constitute the alternative sources of feed available for the stock and the ex ante clause merely refers to a problem which lies in the future. Although the concept of feed \{budgeting has now been oversimplified, it can be seen to have the elements of a classical resource allocation problem; a range of alternative resources or feed supplies, a number of possible products, risk, uncertainty and time. Lastly, feed supplies are functionally affected by the 
animals carried and vice versa. This interaction of animals with their feed is one of the most confusing elements in feed budgeting and will be referred to again.

Traditionally the breeding ewe has been considered as the basis in demonstrating the technique of feed budgeting. Although dry sheep, cattle, or milking cows could be used successfully, the feed requirements of breeding ewes change dramatically through the year and highlight the problems of and need for careful feed budgeting.

The daily feed requirements of the ewes for the year are matched with the 'anticipated pasture growth and the known and expected feed reserves.

Feed budgeting as such involves this matching of 'animal demand with the feed supplies. Although periods of one year are generally chosen, especially when long-term feed conservation is practised, shorter periods may be quite appropriate.

In order to demonstrate the technique of feed budgeting, daily feed requirements of the animal (in this case a breeding ewe) are plotted over a period of one, year. This is illustrated in Fig. 1.

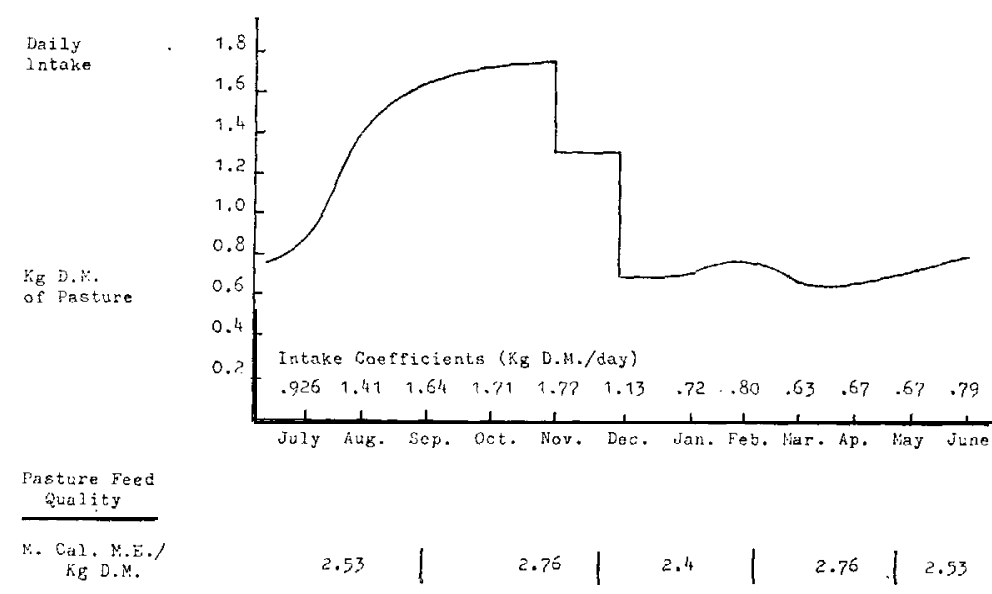

FIG. 1: Daily feed requirement of a breeding ewe.

The breeding ewe weighs $55 \mathrm{~kg}$ and is lambing in mid-August; weaning occurs after 12 weeks. The intake figures have been prepared following Coop (1965) land Jagusch (1973).

The average monthly intake figures can be converted into an approximation of daily intake by drawing a smooth curve between monthly co-ordinates. It is now possible' to extrapolate 
from this curve for any number of ewes per hectare by using the relevant multiples (24.7 ewes/ha (10/acre), 10 ewes/ha (4/ acre) and so on).

These data must then be compared with the expected pasture growth. Figure 2 depicts the expected pasture growth curve for dry and irrigated soils at Winchmore, obtained from J. E. Radcliffe (pers. comm.) . Surpluses can be held in situ for short time periods or conserved conventionally to overcome deficits. This, in its simplest form, is the principle of feed budgeting. However, to satisfy the objective which is to improve animal production in order to maximize profits, the planner must manipulate both the feed demand and the feed supply.

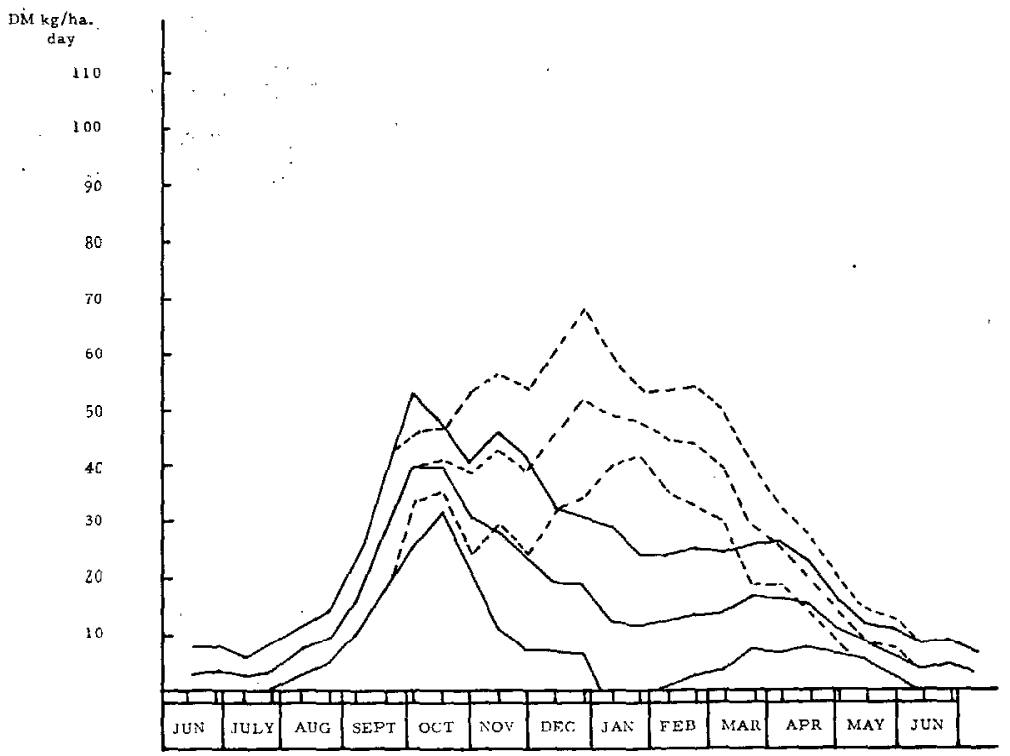

FIg. 2: Partially adjusted feed supplies. Fertile pasture production on Lismore soils. Solid line, dryland; broken line, irrigated.

\section{THE MANIPULATION OF STOCK REQUIREMENTS}

Manipulation of the demand curve will be examined more closely. First, the bump (caused by rising foetal and lamb requirements) can be advanced or retarded by altering the lambing date. Secondly, rhe terminal point of the bump can be altered by 
changing the date of weaning. Thirdly, the height of the bump can be altered by encouraging or restricting multiple births. fourthly, by forcing the animal to live on body fat while not pregnant or feeding a lamb, daily intake figures can be reduced within reason for short durations. Finally, the total curve is moved upwards or downwards by increasing or reducing the stocking rate.

It is worth remembering that the first four adjustments are generally made to allow stock numbers to be increased on the assumption that it will be profitable to do so. This is not always the case.

Each of the adjustments listed is a realistic management ploy used by most farmers to vary stock demands. However, reference to breeding ewes alone has prevented exploration of other vital management apportunities - combinations of dry and breeding stock as well as cattle. It is now almost possible to fit stock demands to any given feed supply pattern. If agistment or the purchase and sale of stock is added to the alternatives, any extraordinary feed supply pattern can be coped with, though money may be lost in doing so.

Since the management problem is analogous to fitting a number of flexible pieces into a variable mould, both parts must be closely studied. The stock are the flexible pieces; the feed supply is the mould. Although adjustments can be made to both of these it is necessary to use some criterion to select the most desirable alternatives. The criterion chosen here is the maximization of profits. However, for any individual farmer, this will probably have to be constrained by minimal increases in labour and risk as well as other allowances reflecting the farmer's own personal preferences. It is important to be reminded of this before looking at tha potentiall modifications to the feed supply as many perfectly simple alternatives must be rejected on the grounds of cost, work involved, risk, or unacceptability for less tangible reasons.

\section{THE ADJUSTMENTS TO FEED SUPPLIES}

The most obvious modifications to the feed supply are obtained by using fertilizer. If the decision to use fertilizer is made on the assumption that by growing more grass profits will be increased, the criterion to maximize profits will not necessarily have been satisfied. Surplus feed will either be wasted or conserved for use in periods of shortage. If this fertilizer policy promotes 
further growth of uncontrollable surplus feed but has only limited effect on periods of feed shortage, it will not necessarily have been the correct decision. Although the fertilizer applied may certainly increase profits, the best possible decision will maximize profits.

Clearly, there are many alternatives. If it is assumed that feed shortages usually occur within the "period late July to early September, the feed supply could have been improved by buying feed, using nitrogen in early winter or by providing greenfeed and forage crops. The demand for food could also have been adjusted. Fewer ewes, more dry stock, agistment, a total reductioa in stock numbers with an associated increase in per-head performance; 'and, lastly, the most important decision in such circumstances - later lambing.

A delay in the lambing date reduces the demand for winter feed by approximately $1 \%$ per day for every day lambing is set back. For instance, a 10-day delay reduces the demand $10 \%$. The important point is that one or more of these adjustments could have given greater profits than topdressing. Feed budgeting allows the effects of each of these changes to be quantified to enable a choice to be made between them.

Apart from feed conservation in situ for a number of weeks as saved grass or a few months as fodder crop, feed may be stored as hay, haylage, silage, grain, or pellets for itwo or more years. The feed supply problem can now be specified as a conventional inter-temporal resource allocation problem, which is really a problem of determining how much feed to use and when. Rut again decisions have to be made by referring to the objective function.

It will be useful to list the alternatives available to alter the feed' supply (expressed graphically as quantities available at points in time) .

(1) Feed purchases (shifts portions of the feed supply curve upwards).

(2) Feed transfers - conservation (shifts portions of the feed supply curve forwards).

(3) The introduction of new species with more vigorous growth or a different growth pattern from the resident pasture species or forage crops (shifts all or portions of the curve upwards). 
(4) Changes in the resources affecting plant growth:

(a) Additions; soil minerals through fertilizers and soil moisture by irrigation.

(b) Protection; drainage and shelter. (Both actions shift all or portions of the curve upwards.)

(5) Grazing management (shifts all or portions of the curve upwards or downwards).

The fifth point is perhaps the most important as bad grazing management will negate all the gains made by adjustments to either feed supplies or stock requirements. Conversely, good management practices improve stock performance and increase feed supplies, Unfortunately, grazing management studies are difficult and precise quantitative estimates for year-long studies are often not repeatable. However, if it is borne in mind that from 80 to $85 \%$ of New Zealand's overseas income is earned by pastoral production and every pastoral 1 farmer has to practise grazing management, the need for study in this 'area is evident.

\section{GRAZING MANAGEMENT}

Perhaps the effects of grazing management on pasture production should be considered further. Stock have significant detrimental effects on feed supplies through trampling (Edmond, 1958) or 'overgrazing (Brougham. 1959). Trampling effects are more significant when soils are saturated or stock are moved on to feed carelessly. Further, subjective evidence suggests that trampling damage is some exponential function of stock numbers. Overgrazing can result from mismanaged rotational grazing or s.et-stocking at excessive rates. In both cases, if the practice is prolonged pasture production may be permanently impaired and stock production will decline.

Conversely, careful grazing management will ensure that pastures reach their optimum productivity by effectively pruning the pasture instead of clearfelling it as is the situation with overgrazing. Brougham (1959) discusses this optimum height of grazing.

Another way in which careful grazing management improves pasture productivity is by affecting palatability and subsequent pasture utilization. Controlled grazing during the period of seedhead emergence when pasture digestibility is declining (Minson, 1963) is particularly important. Pasture control with ewes and lambs is hard to effect at this period, especially on hill country, 
and in most instances cattle are used for this purpose. This complementary function of cattle is often overlooked and it is in this regard also that differences between sheep breeds are noticeable. There is a great deal to learn in this area. Further, as stock numbers rise, nutrients are recycled faster and pasture growth may be increased, but at some point these gains are offset by the loss in production associated with the increased trampling losses and the extra work involved. This poses a most interesting conundrum - what is the optimum stocking rate?

One is forced to use the constrained profit maximizing criterion to determine this.

To this point the paper has set out the major adjustments which are possible to the feed supply and stock requirements and the interactions of the stock with their feed. A careful look at the problem of quantification is now required. How can feed supply and demand be accurately correlated?

\section{THE QUANTITATIVE APPROACH TO FEED BUDGETING}

For many years researchers and consultants have used dry matter as the basis for reconciling feed supplies and stock requirements. Jagusch (1973) has discussed a modification of this which takes into account variations in feed quality by describing feed in terms of its metabolizable energy content per kilogram as well as the limitations imposed on 'appetite by the fibre content of the feed. The quantitatively correct method of feed budgeting must account for each of these variables and also allow for variations in palatability. The palatability of feed has not been incorporated in the feed budgeting technique in anything but a subjective manner in the past. Indeed, objective measurements accounting for all variables impose difficulties.

Simple correlation of dry matter requirements with the dry matter of feed available can lead to errors through not accounting adequately for the variables described but the procedure is still useful especially as a guide to short-term grazing management .

In this respect animal requirements can be specified precisely; feed may be of relatively uniform metabolizable energy content and the problem remains of accurately estimating the dry matter available for the animals. Logically the dry matter available is a function of pasture length and density. The relationship between these two variables has been demonstrated by Frengley (1971) 
based subjectively on measurements by Suckling (1964) and Brougham (1959). If variations in feed quality and palatability are not particularly significant, the feed budgeting technique can be used very effectively to improve grazing management decisions. It is noticeable that the subjective estimates of available dry matter by consultants improve rapidly with practice. The technique is being used very successfully by dairy farmers and their consultants in the winter-spring period and by fat lamb farmers during the winter and for beef cattle. As stocking rates increase, feed budgeting becomes more important and there are few efficient farmers seeking to maximize profits who do not practise feed budgeting at least in some form. As more people become familiar with the quantitative approach to feed budgeting and as stocking rates continue to rise, feed budgeting, whether in megacalories, metabolizable energy, dry matter, cow or ewe grazing days, will become one of the most important aids to effective grazing management.

Finally, the main points might be summarized:

(1) There will be considerable confusion among people who use the technique for research or farm management purposes unless they clearly state their objective. In this paper reference has been made throughout to the maximization of profits as the objective, subject to a number of constraints. If the objective was to maximize total annual dry matter ingested, the decision would change.

(2) There are many alternatives available to alter feed supplies or stock requirements. The correct selection from these cannot be made unless the objective is known. Adjustment to animal intake is often overlooked in an attempt to maintain feed supplies. Likewise, acceptable adjustments to feed supplies are often not considered because lagged effects on animal production are ignored as in the case of feed purchases or agistment.

(3) Effective feed budgeting in pastoral situations is the basis of efficient farm management. It is an 'ancient art. As the subjective elements are removed and objectivity increases it is becoming a science To be applied effectively in farm management the technique must be accurate and simple. Although seasonal uncertainty will not be eliminated, preparedness for poor seasons will improve significantly and profits will increase. 
The paper has set out the main alternatives which have to be considered by individuals using feed budgeting as an aid to farm management. The need to specify an objective and its relevance in planning have been explained. Although the paper has not been drawn into the form of a simulation model to explore feed budgeting alternatives, the principal variables, have been elaborated. The delight and difficulties of deriving appropriate mathematical models with which to explore pertinent feed budgeting problem's have been beyond the scope of this paper which has had to outline the principles rather than the. actual practice of feed budgeting. The opportunities for research in this area are unlimited but such research may best be approached in a multi-disciplinary farm management framework which should embrace pastoral, animal and economic considerations at least.

I look forward to rapid development in the future application of the feed budgeting technique.

\section{REFERENCES}

Brougham. R. W., 1959: N.Z. /l agric. Res., 2: 283-96.

Coop, I. E., 1965: N.Z. agric. Sci., 1 (3): 13-8.

Edmond, D. B., 1958: N.Z. $f l$ agric. Res., 1: 319-28.

Frengley, G. A. G., 1971: Lincoln College Department of Farm Management \& Rural Valuation, Farm Budget Manual. Part 1, Technical: 75-83.

Jagusch, K. T., 1973: Livestock production from pasture. In: Pasture and

Pasture Plants, ed. R. H. M. Langer, pp. 229-42. Reed, Wellington.

Minson, D. J., 1963: Massey Dairyfmg A.: 127-34.

Suckling, F. E. T., 1964: Proc. N.Z. Grassld Ass., 26: 137-52. 